\title{
Longevidade e sensibilidade de helicônias ‘Golden Torch’ ao etileno exógeno(1)
}

\author{
SANDRA OLIVEIRA DE SOUZA(2), MARIAAUXILIADORA COÊLHO DE LIMA(3), FERNANDO LUIZ FINGER(2), \\ AGNELLI HOLANDA OLIVEIRA(4) E JOSÉ GERALDO BARBOSA ${ }^{(2)}$
}

\begin{abstract}
RESUMO
Neste trabalho, objetivou-se avaliar o efeito do etileno exógeno na longevidade e sensibilidade de helicônias 'Golden Torch' armazenadas em condições ambiente. As inflorescências foram colhidas com duas brácteas expandidas e uma fechada, em área de produção comercial localizada em Petrolina-PE. Os tratamentos consistiram de doses de ethephon $(0 ; 0,1 ; 1 ; 10$; 100 e $\left.1.000 \mathrm{mg} \mathrm{L}^{-1}\right)$ e datas de avaliação das hastes (0, 2, 4, 6, 8 e 10 dias, a 20,4 $\pm 3,7^{\circ} \mathrm{C}$ e $\left.49 \pm 11 \% \mathrm{UR}\right)$. O delineamento experimental foi inteiramente casualizado, em fatorial 6 × 6, com 4 repetições de 4 hastes. Foram observadas perdas de massa fresca, aparência, luminosidade e croma das brácteas com o aumento das concentrações de ethephon e do tempo de armazenamento. O ângulo Hue das brácteas que receberam 100 e $1.000 \mathrm{mg} \mathrm{L}^{-1}$ de ethephon indicou coloração menos laranja. O consumo de água pelas inflorescências decresceu com o tempo de armazenamento, independente dos tratamentos com ethephon. A longevidade de inflorescências somente foi reduzida com as doses mais altas: 100 e $1.000 \mathrm{mg} \mathrm{L}^{-1} \mathrm{de}$ ethephon, que a restringiram a dois e quatro dias, respectivamente. Por tais razões, as hastes de helicônias 'Golden Torch' caracterizaram-se como pouco sensíveis ao etileno exógeno.

Palavras-chave: Heliconia psittacorum x H. spathocircinata, ethephon, senescência.
\end{abstract}

\begin{abstract}
Longevity and sensitivity of heliconia 'Golden Torch' to exogenous ethylene

In this study, it was aimed to evaluate the effect of exogenous ethylene on longevity and sensitivity of heliconia 'Golden Torch' stored under ambient conditions. Inflorescences were harvested with two expanded bracts and one closed bract, from a commercial area, located in Petrolina, Pernambuco State, Brazil. The treatments consisted of doses of ethephon $(0$, $0.1,1,10,100$ and $1,000 \mathrm{mg} \mathrm{L}-1)$ and evaluation time $\left(0,2,4,6,8\right.$ and 10 days, at $20.4 \pm 3.7{ }^{\circ} \mathrm{C}$ and $\left.49 \pm 11 \% \mathrm{RH}\right)$. The experimental design was a completely randomized, in a 6 x 6 factorial arrangement with four replications of four stems. It was observed a decrease on fresh weight, appearance, lightness and chroma of bracts when the concentrations of ethephon and evaluation time increased. The Hue angle of the bracts that received 100 and $1.000 \mathrm{mg} \mathrm{L}^{-1}$ of ethephon indicated a lighter orange color. The water uptake of the inflorescences decreased with storage time, independent of the treatments with ethephon. The longevity of inflorescences was reduced only with the higher doses: 100 and $1.000 \mathrm{mg} \mathrm{L}^{-1}$ of ethephon, which restricted it to two and four days, respectively. For those reasons, the heliconia 'Golden Torch' bracts were characterized as low sensitive to ethylene.
\end{abstract}

Keywords: Heliconia psittacorum x H. spathocircinata, ethephon, senescence.

\section{INTRODUÇÃO}

A produção brasileira de flores e plantas ornamentais está distribuída principalmente nos estados de São Paulo, do Rio de Janeiro, de Minas Gerais, de Santa Catarina e do Rio Grande do Sul (LANDGRAF e PAIVA, 2009). Na região Nordeste, Pernambuco é o primeiro produtor nacional de flores tropicais e o quinto de flores tradicionais, que são predominantemente originárias de clima subtropical e temperado. De 197 produtores que exploram uma área de 125 hectares nesse Estado, 32 deles cultivam flores tropicais (70 hectares) e 165, flores de clima temperado (em 55 hectares), organizados em quatro associações e uma cooperativa, movimentando recursos da ordem de $\mathrm{R} \$ 36$ milhões/ano e gerando 800 empregos diretos e milhares de indiretos. Recentemente, uma nova região, o Vale do São Francisco, vem surgindo como polo de produção e o centro de referência é a cidade de Petrolina, a $700 \mathrm{~km}$ de Recife (SEBRAE, 2008).
Entre as flores de corte cultivadas na região, destacam-se as helicônias, muito apreciadas em função da beleza, exuberância e longevidade. Entre as mais cultivadas no Brasil, destacam-se as H. psittacorum x H. spathocircinata Aristeguieta, entre elas a cultivar Golden Torch, híbrido natural de pequeno porte com inflorescência terminal e ereta, apresentando de quatro a oito brácteas de cor amarelo-alaranjada com flores alaranjadas em seu interior (CASTRO et al., 2007). Apesar das amplas possibilidades de exploração comercial de flores e folhagens de corte no Brasil, as grandes distâncias geralmente percorridas até o consumidor ocasionam perdas de até $35 \%$ para alguns produtos (JUNQUEIRA e PEETZ, 2002). No caso das flores de corte, a longevidade pode ser afetada por diversos fatores endógenos e exógenos, na pré e na pós-colheita, como extremos de temperatura, presença de etileno e qualidade da água (NOWAK e RUDNICKI, 1990).

\footnotetext{
(1) Trabalho recebido para publicação em 16/04/2012 e aprovado em 24/04/2014

(2) Universidade Federal de Viçosa, Dep. de Fitotecnia, CEP 36571-000, Viçosa, MG. E-mail: sandraosouza@yahoo.com.br;

(3) Embrapa Semiárido, Caixa Postal 23, CEP 56300-970, Petrolina, PE.

(4) Embrapa Agroindústria de Alimentos, Planta V, CEP: 23020-470, Rio de Janeiro, RJ.
} 
O etileno é o regulador de crescimento que induz a expressão de diversos genes durante a senescência de órgãos florais. Em flores tropicais sensíveis à ação do etileno, ele induz a murcha e o secamento das pétalas, seguido geralmente de abscisão (FINGER e BARBOSA, 2005). Para retardar a senescência em várias espécies de flores, podem-se fazer uso de técnicas que reduzam o efeito do etileno, repercutindo na diminuição da taxa respiratória, ou mesmo tornando os tecidos menos sensíveis ao etileno. $\mathrm{O}$ uso de métodos como inibição da produção, bloqueio do sítio receptor ou remoção do etileno do ambiente vem sendo comumente usado para frutos, olerícolas e flores (SEREK et al., 2006).

A sensibilidade da planta ao etileno depende da presença de receptores específicos nos tecidos. O nível de sensibilidade das flores ao etileno varia muito entre as espécies e, até mesmo, entre variedades da mesma espécie. Em razão desses efeitos, as flores podem ser agrupadas em muito sensíveis, pouco sensíveis ou insensíveis ao etileno (DIAS-TAGLIACOZZO et al., 2005).

Algumas flores altamente sensíveis ao regulador de crescimento respondem a concentrações tão baixas quanto 1 a $3 \mu \mathrm{L} \mathrm{L}^{-1}$, por 24 horas de exposição, enquanto flores menos sensíveis são resistentes a concentrações 10 a 100 vezes maiores (NOWAK e RUDNICKI, 1990). Estudo realizado por Woltering e Van Doorn (1988) com 93 espécies representadas por 23 famílias revelou que as flores que respondiam a baixas concentrações de etileno exógeno são provavelmente aquelas em que o regulador de crescimento estaria envolvido naturalmente na senescência. Assim, conforme os diferentes graus de sensibilidade ao etileno, as espécies variam de insensíveis, como Strelitzia reginae, a muito sensíveis, como gladíolos, cravos e orquídeas (FINGER e BARBOSA, 2006). Tanase et al. (2008) mencionaram que, apesar de flores de cravos 'Sandrosa' apresentarem longevidade maior (15,4 dias) que 'White Sim' (7,6 dias), ambas as cultivares possuem a mesma sensibilidade ao etileno. Elgar et al. (1999) afirmaram que a exposição de algumas cultivares de lírio (híbrido Oriental e Lilium longiflorum) a $100 \mu \mathrm{L} \mathrm{L}^{-1} \mathrm{de}$ etileno exógeno não afetou a vida de vaso, enquanto que em outras cultivares (híbrido asiático), a qualidade e a longevidade foram ligeiramente reduzidas.

No entanto, em helicônias, estudos desta natureza ainda não foram realizados. Desta forma, torna-se imprescindível estudar a influência do etileno na senescência desta espécie, já que este regulador de crescimento é capaz de reduzir consideravelmente a vida de vaso e afetar a qualidade pós-colheita de muitas espécies de flores de corte.

Nesse sentido, o objetivo deste trabalho foi avaliar a longevidade e a sensibilidade de helicônias 'Golden Torch' ao etileno exógeno, em armazenamento sob condições ambiente.

\section{MATERIAL E MÉTODOS}

A colheita das inflorescências ou hastes florais de helicônia 'Golden Torch' foi realizada no mês de setembro de 2007, pela manhã ( 8 horas), em uma área de produção comercial localizada no município de Petrolina-PE (latitude $9^{\circ} 9^{\prime}$ 'Sul e longitude $40^{\circ} 29^{\prime}$ Oeste, altitude de 365,5 m), quando apresentavam, por ocasião da colheita, duas brácteas expandidas e uma bráctea fechada (conhecida por ponteiro).

Após a colheita, as inflorescências de helicônias 'Golden Torch' foram transportadas ao Laboratório de Fisiologia Pós-colheita da Embrapa Semiárido, onde foram submetidas a procedimentos de seleção e à remoção das folhas e padronização do comprimento da haste $\mathrm{em} 60 \mathrm{~cm}$, desde a seção do corte até a região próxima ao pedúnculo. Em seguida, as hastes florais foram submetidas aos tratamentos, que consistiram de doses de ethephon $(0 ; 0,1 ; 1 ; 10 ; 100 \mathrm{e}$ $\left.1.000 \mathrm{mg} \mathrm{L}^{-1}\right)$ e datas de avaliação das hastes $(0,2,4,6,8 \mathrm{e}$ 10 dias). O ethephon foi aplicado por pulverização manual, com auxílio de um borrifador, até o escorrimento do produto. Os tratamentos foram realizados para todas as hastes em um mês no mesmo ambiente, sendo as inflorescências, em seguida, colocadas em água destilada e mantidas, separadamente conforme a dose de ethephon aplicada, em armazenamento sob condições de temperatura de 20,4 $\pm 3,7$ ${ }^{\circ} \mathrm{C}$, em umidade relativa do ar de $49 \pm 11 \%$ e luminosidade de 460 lux.

Durante o armazenamento das inflorescências, a cada dois dias foram realizados a quantificação das variáveis, os recortes na base das hastes com cerca de $2 \mathrm{~cm}$ e a troca de água contida nos recipientes. Estes recipientes foram fechados, na sua parte superior, com poliestireno expandido com três orifícios por onde as hastes foram introduzidas.

Quanto às avaliações, foram consideradas e descritas as seguintes características de qualidade:

a) Massa fresca (\% da massa fresca inicial): obtida por meio de uma balança semi analítica.

b) Consumo de água $\left(\mathrm{mL} 2\right.$ dias $\left.^{-1} 100 \mathrm{~g}^{-1}\right)$ : realizado a partir do segundo dia, sendo estimado pela diferença média entre o volume inicial colocado no vaso, medido em proveta graduada ( $1.000 \mathrm{~mL}$ de capacidade), e o volume de água obtido no final de cada avaliação.

c) Abertura floral: estimada por meio de uma escala subjetiva de notas, pela formação de um novo ponteiro e da expansão da terceira bráctea formada (SOUZA, 2008). Essa escala atribuiu nota 1 às inflorescências que apresentavam duas brácteas abertas e o ponteiro; nota 2 às inflorescências com duas brácteas abertas e início de abertura do ponteiro, formando a partir daí uma terceira bráctea; nota 3 às inflorescências com a terceira bráctea parcialmente expandida com relação ao ponteiro; nota 4 quando a terceira bráctea estava expandida, formando um ângulo de, aproximadamente, $45^{\circ}$ com o ponteiro; e nota 5 às inflorescências com três brácteas abertas totalmente expandidas e com o ponteiro (Figura 1).

d) Cor das brácteas: determinada por meio de colorímetro digital portátil (modelo ColorTec- $\mathrm{PCM}^{\mathrm{TM}}$ ), utilizando-se os atributos luminosidade (L), croma (C) e ângulo Hue (H). $\mathrm{O}$ atributo $\mathrm{L}$ indica a variação da coloração de preta à branca, em uma escala de 0 a 100 . O H corresponde à cor, cujos valores variam de 0 a $360^{\circ}$. O C indica a intensidade ou pureza da cor, representado por valores desde 0 até 60 .

e) Aparência: avaliada por meio de escala subjetiva de notas de 5 a 1 , em que se atribuiu 5 à haste, e/ ou bráctea túrgida de coloração laranja; 4 , ao início de mudança da coloração da haste, de verde para a verde amarelada, e/ ou da bráctea, que passa de laranja à laranja avermelhada; 3 , 


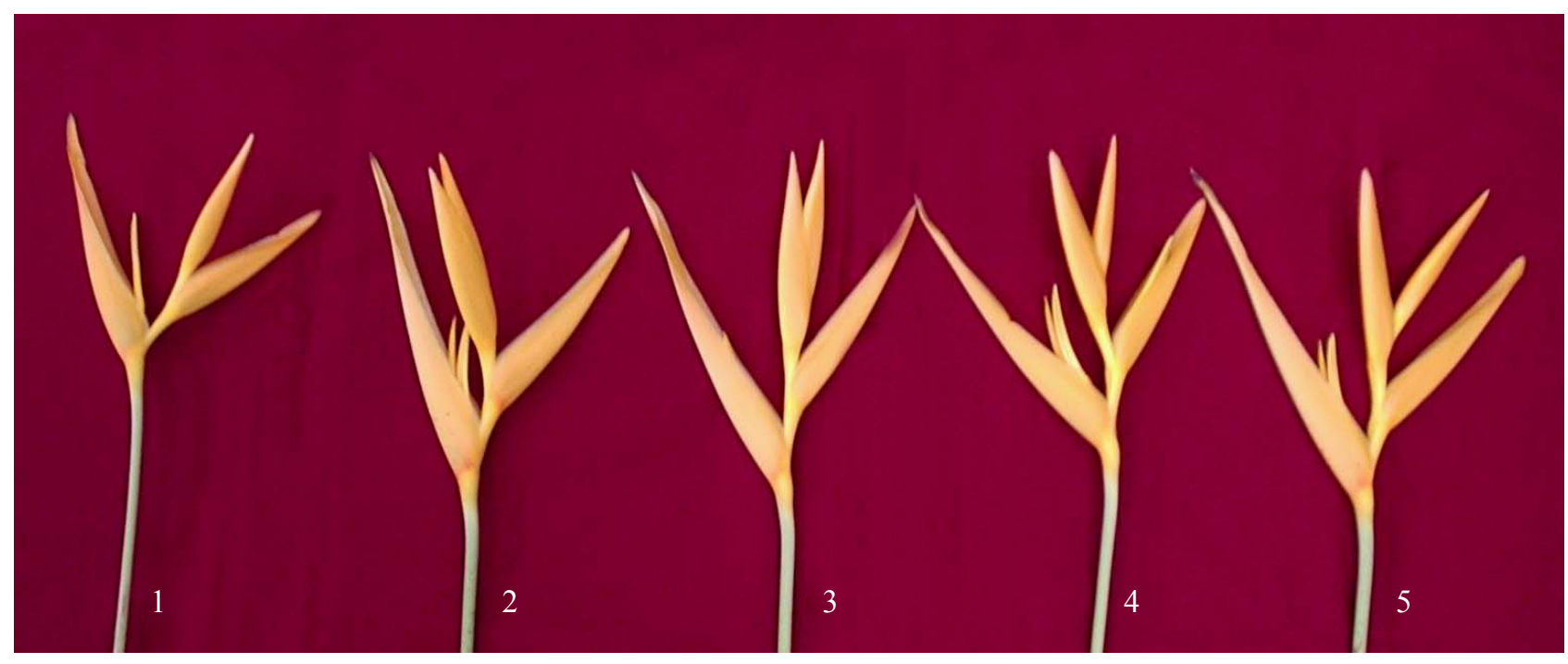

Figura 1. Abertura floral em helicônia ‘Golden Torch' representada por escala subjetiva de notas (1 a 5). As notas atribuídas representavam a seguinte observação visual: 1- inflorescências com duas brácteas abertas e o ponteiro; 2inflorescências com duas brácteas abertas e início de abertura do ponteiro, formando a partir daí uma terceira bráctea; 3- inflorescências com a terceira bráctea parcialmente expandida em relação ao ponteiro; 4- terceira bráctea expandida, formando um ângulo, perpendicular ao ponteiro; e 5- inflorescências com três brácteas abertas totalmente expandidas e com o ponteiro. Petrolina, PE, 2007. Fonte: Souza (2008).

Figure 1. Flower opening in heliconias 'Golden Torch' according a subjective scale (1-5). The notes awarded represented the following visual observation: 1 - inflorescences with two open bracts and the pointer; 2 - inflorescences with two open bracts and pointer top opening, forming a third bract; 3 - inflorescences with the third bract partially expanded in relation to the pointer; 4 - third bract expanded at an angle perpendicular to the pointer and 5 - inflorescences with three bracts open fully expanded and with the pointer. Petrolina, Pernambuco State, Brazil, 2007. Source: Souza (2008).

à perda de turgidez da haste e da bráctea, com desidratação pronunciada nas extremidades da última; 2 , à presença de pequenas manchas, perda de turgidez e mudança de cor acentuadas na haste e/ ou na bráctea; e 1, à necrose e manchas acentuadas na haste e/ ou na bráctea.

f) Longevidade: estimado em percentual de inflorescências que receberam notas de aparência visual superior a 2 durante o armazenamento, uma vez que valores iguais ou abaixo da citada nota correspondem à não aceitação comercial.

O experimento foi instalado em delineamento inteiramente casualizado, em esquema fatorial $6 \times 6$ (dose de ethephon x data de avaliação), com 4 repetições e 4 hastes por parcela. Os dados foram submetidos a análises de variância e de regressão. Os modelos foram escolhidos com base no significado biológico da variável, no coeficiente de determinação e na significância dos coeficientes de regressão, utilizando-se o teste "t", a 1 e $5 \%$ de probabilidade. Foram adotadas equações polinomiais de até segundo grau para todas as variáveis estudadas, com exceção da luminosidade e do ângulo Hue, que, em alguns casos, foram ajustadas para estas equações de terceiro grau. Tais equações só foram adotadas quando os coeficientes de determinação consistiram de valores até o limite de $60 \%$ e a significância dos coeficientes de regressão maior que $5 \%$ de probabilidade pelo teste " $\mathrm{t}$ ". Para as variáveis nas quais estes critérios não foram atendidos, optou-se por apresentar os valores médios em cada tempo de armazenamento ou cada dose de ethephon utilizada.

\section{RESULTADOS E DISCUSSÃO}

Houve efeito significativo da interação dos fatores dose de ethephon e data de avaliação sobre os teores de massa fresca, luminosidade, croma, ângulo Hue, aparência e longevidade. Quanto à avaliação de abertura floral, foi evidenciado efeito isolado das doses de ethephon e das datas de avaliação, estas representando o tempo de armazenamento. Por sua vez, o consumo de água foi somente influenciado pelo tempo de armazenamento.

A massa fresca das hastes florais tratadas com $0,1,10$ e $1.000 \mathrm{mg} \mathrm{L}^{-1}$ de ethephon aumentou em $0,89 \%, 0,50 \%$, $0,31 \%$ e $0,78 \%$ até o terceiro dia de armazenamento (Figura 2A). Após o período, o decréscimo observado indicou que a perda foi mais veloz do que a absorção de água. Houve decréscimo gradual, desde o dia da colheita até ao décimo dia de avaliação, no teor de massa fresca das hastes tratadas com $0,1 \mathrm{mg} \mathrm{L}^{-1}$ do produto. Apesar das hastes tratadas com 100 de ethephon obtiverem um modelo quadrático na regressão polinomial, o aumento de massa fresca ocorrido até o segundo dia foi pequeno, seguido de decréscimo até o décimo dia de armazenamento. 


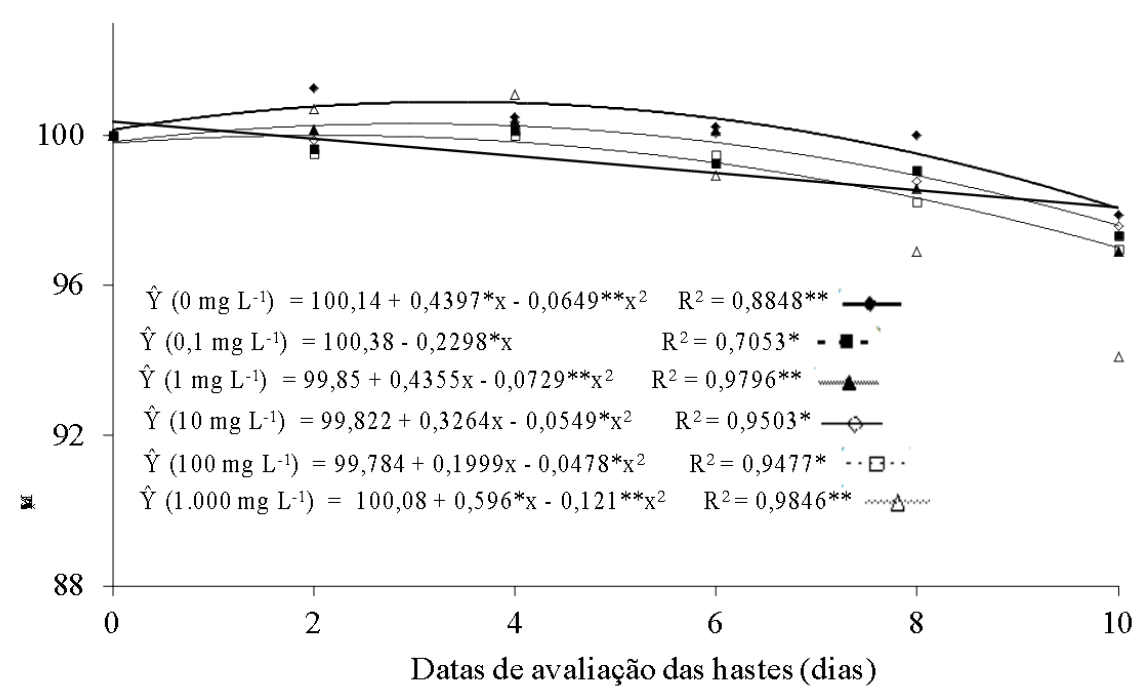

(A)

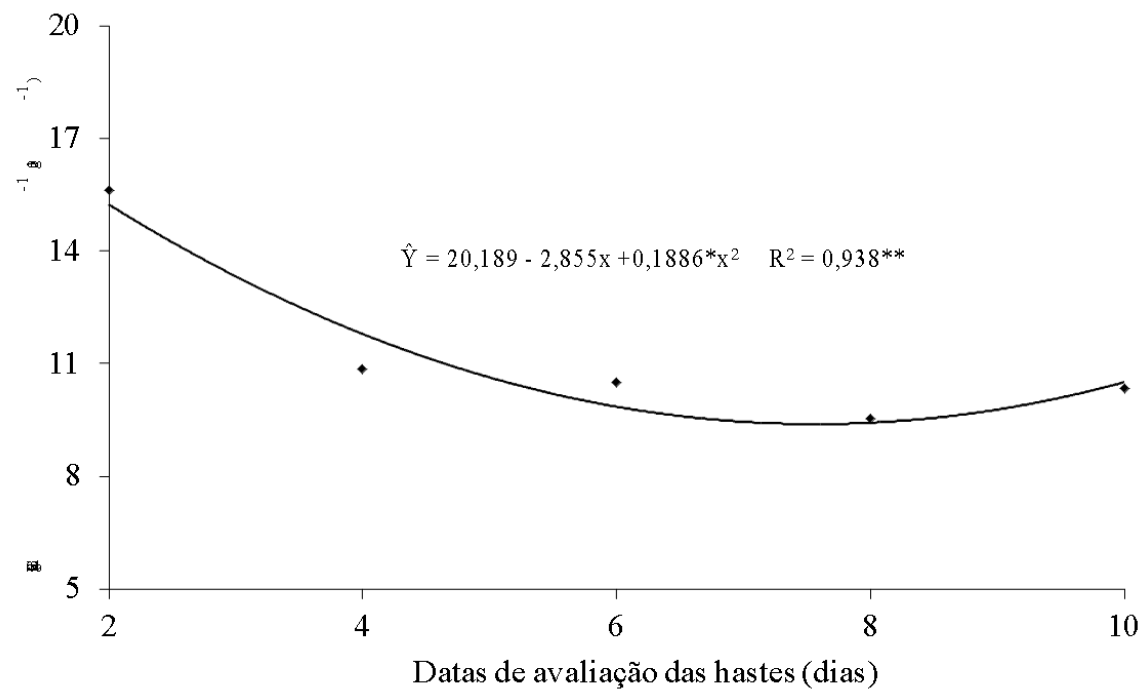

Figura 2. Teor de massa fresca (A) e consumo de água (B) de inflorescências de helicônias 'Golden Torch' tratadas com $0 ; 0,1 ; 1 ; 10 ; 100$ e $1.000 \mathrm{mg} \mathrm{L}^{-1}$ de ethephon, durante dez dias de armazenamento $\left(20,4 \pm 3,7^{\circ} \mathrm{C}\right.$ e $\left.49 \pm 11 \% \mathrm{UR}\right)$. Petrolina, PE, 2007. m.f.= massa fresca.

$\left(^{*}\right)$ e $(* *)$, significativos a $5 \%$ e a $1 \%$ de probabilidade, pelo teste "t", respectivamente.

Figure 2. Fresh mass (A) content and water uptake (B) of heliconias 'Golden Torch' inflorescences treated with 0 , $0.1,1,10,100$ and 1,000 $\mathrm{mg} \mathrm{L}^{-1}$ of ethephon, for 10 days of storage $\left(20.4 \pm 3.7^{\circ} \mathrm{C}\right.$ and $\left.49 \pm 11 \% \mathrm{RH}\right)$. Petrolina, Pernambuco State, Brazil, 2007. m.f. = fresh mass.

(*) and (**), significant at $5 \%$ and $1 \%$ probability by " $t$ " test, respectively.

As perdas de massa fresca ocorridas em inflorescências tratadas com ethephon nas doses de $0 ; 0,1 ; 1 ; 10 ; 100$ e $1.000 \mathrm{mg} \mathrm{L}^{-1}$ no final do armazenamento foram de $1,9 \%$, $1,9 \%, 3,1 \%, 2,4 \%, 3,0 \%$ e $6,1 \%$, respectivamente (Figura $2 \mathrm{~A}$ ). Essa resposta ao uso do etileno exógeno deve-se, além do aumento na perda gradual da turgescência das células, ao maior consumo de substratos durante a respiração (GAGO e MONTEIRO, 2011), contribuindo para o avanço dos sintomas de senescência e consequente perda de qualidade do produto. Os avanços desses eventos fisiológicos são expressos como murchamento, escurecimento das brácteas e/ ou abscisão de flores. No presente estudo, eles foram observados, principalmente, nas hastes tratadas com $1.000 \mathrm{mg} \mathrm{L}^{-1}$ de ethephon. Efeito semelhante foi rela- tado em estudo com rosas de corte 'First Red', em que os menores teores de massa fresca e absorção de água foram observados nas flores submetidas às maiores concentrações de etileno $\left(100 \mu \mathrm{L} \mathrm{L}^{-1}\right)$ durante o armazenamento em condições ambiente (CHAMANI et al., 2005).

$\mathrm{O}$ consumo de água pelas inflorescências de helicônia decresceu desde o segundo $\left(15,2 \mathrm{~mL} 2\right.$ dias $\left.^{-1} 100 \mathrm{~g}^{-1}\right)$ até ao oitavo dia de armazenamento $\left(9,4 \mathrm{~mL} 2 \operatorname{dias}^{-1} 100 \mathrm{~g} \mathrm{~g}^{-1}\right)$, não sendo verificado efeito significativo da aplicação das doses crescentes de ethephon (Figura 2B). Chamani et al. (2005) também observaram que o consumo de água em rosas 'First Red' de corte aumentou até o terceiro dia de armazenamento e, a partir deste período, a perda passou a ser maior do que a absorção, independentemente de as 
flores terem sido tratadas ou não com etileno. No entanto, ao final do armazenamento de rosas 'First Red', houve um decréscimo no consumo de água intensificado quando se usavam as maiores concentrações do produto $\left(100 \mu \mathrm{L} \mathrm{L}^{-1}\right)$.

Entre o oitavo e o décimo dia de armazenamento, houve pequeno aumento no consumo de água pelas inflorescências, que pode ter origem nas variações de temperatura e de umidade relativa do ar ocorrida nesse período específico quando foram registrados aumento de $3,6^{\circ} \mathrm{C}$ e diminuição de $6 \%$, respectivamente. Segundo Van Doorn e Cruz
(2000), fatores como temperatura, qualidade da água de vaso e taxa de transpiração das inflorescências podem contribuir no aumento da taxa de consumo de água.

A abertura floral foi pouco influenciada pelas doses de ethephon e pelo tempo de armazenamento (Figura 3A e 3B, respectivamente). Ao final de dez dias de avaliação, as inflorescências apresentavam duas brácteas abertas e uma em início de expansão. A dose de $1 \mathrm{mg} \mathrm{L}^{-1}$ de ethephon foi a que mais favoreceu o processo de abertura floral em helicônias 'Golden Torch' (Figura 3A).

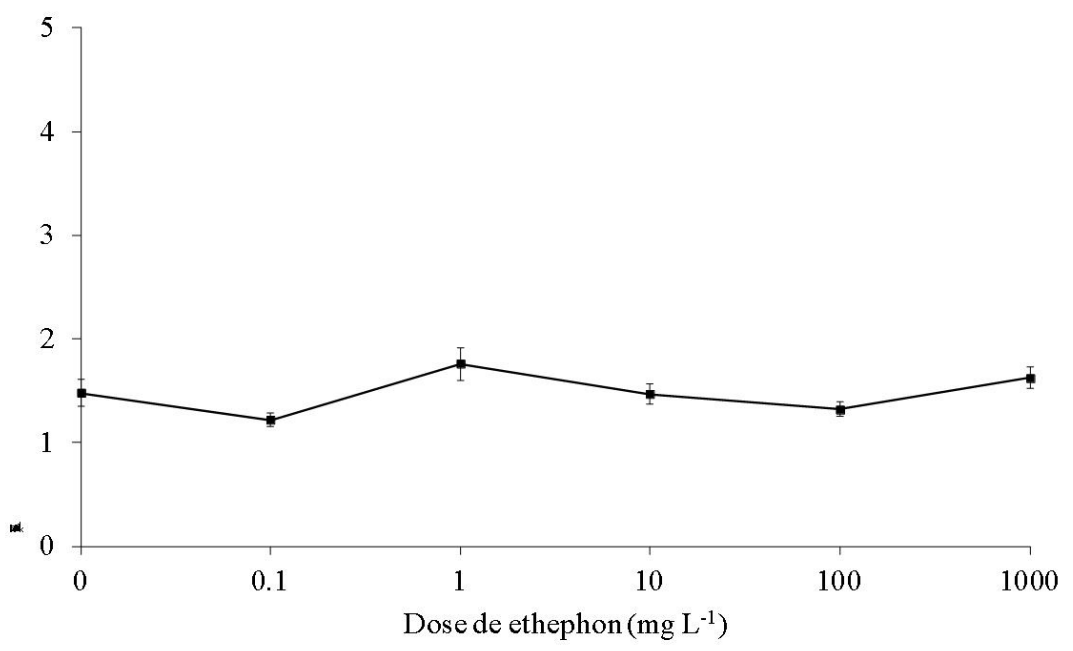

(A)

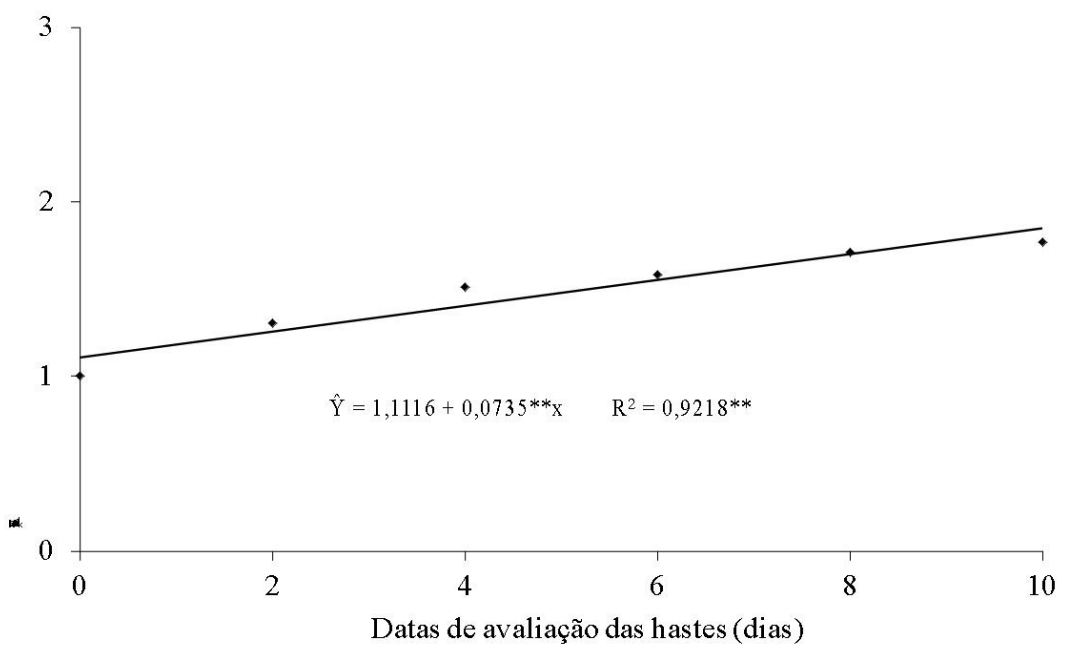

Figura 3. Abertura floral de helicônias 'Golden Torch' tratadas com doses de 0; 0,1; $1 ; 10 ; 100$ e $1.000 \mathrm{mg} \mathrm{L}^{-1} \mathrm{de}^{-}$ ethephon (A) e avaliadas durante dez dias de armazenamento (20,4 $\pm 3,7{ }^{\circ} \mathrm{C}$ e $49 \pm 11 \%$ UR) (B). Petrolina, PE, 2007.

(*) e (**), significativos a $5 \%$ e a $1 \%$ de probabilidade, pelo teste " $t$ ", respectivamente.

Figure 3. Flower opening of heliconias 'Golden Torch' treated with 0, 0.1, 1, 10, 100 and 1,000 $\mathrm{mg} \mathrm{L}^{-1}$ of ethephon (A) and evaluated for 10 days of storage $\left(20.4 \pm 3.7^{\circ} \mathrm{C}\right.$ and $49 \pm 11 \%$ RH) (B). Petrolina, Pernambuco State, Brazil, 2007.

(*) and (**), significant at $5 \%$ and $1 \%$ probability by " $t$ " test, respectively. 
Segundo Imsabai et al. (2010), em flores de lótus ( $\mathrm{Ne}$ lumbo nucifera), o etileno não influenciou a abertura floral. No entanto, em rosas de corte, a abertura floral pode ser estimulada, inibida ou não afetada pelo etileno exógeno (YAMAMOTO et al., 1994), sendo o efeito dependente da cultivar (TAN et al., 2006; MA et al., 2008). Segundo Tan et al. (2006), o etileno inibiu a abertura floral de rosas 'Kardinal' e promoveu a abertura das pétalas em 'Samantha'. Porém, em alguns cultivares de tulipas (Apeldoorn e Frappant) (VAN DOORN et al., 2011) e em inflorescências de Curcuma alismatifolia (Zingiberaceae) (BUNYA-ATICHART et al., 2004), a abertura das flores foi inibida pelo ethephon.

Os atributos de cor luminosidade (L), croma (C) e ângulo Hue das brácteas foram influenciados pelas concentrações de ethephon durante dez dias de armazenamento (Figuras $4 \mathrm{~A}, 4 \mathrm{~B}$ e $5 \mathrm{~A}$, respectivamente).

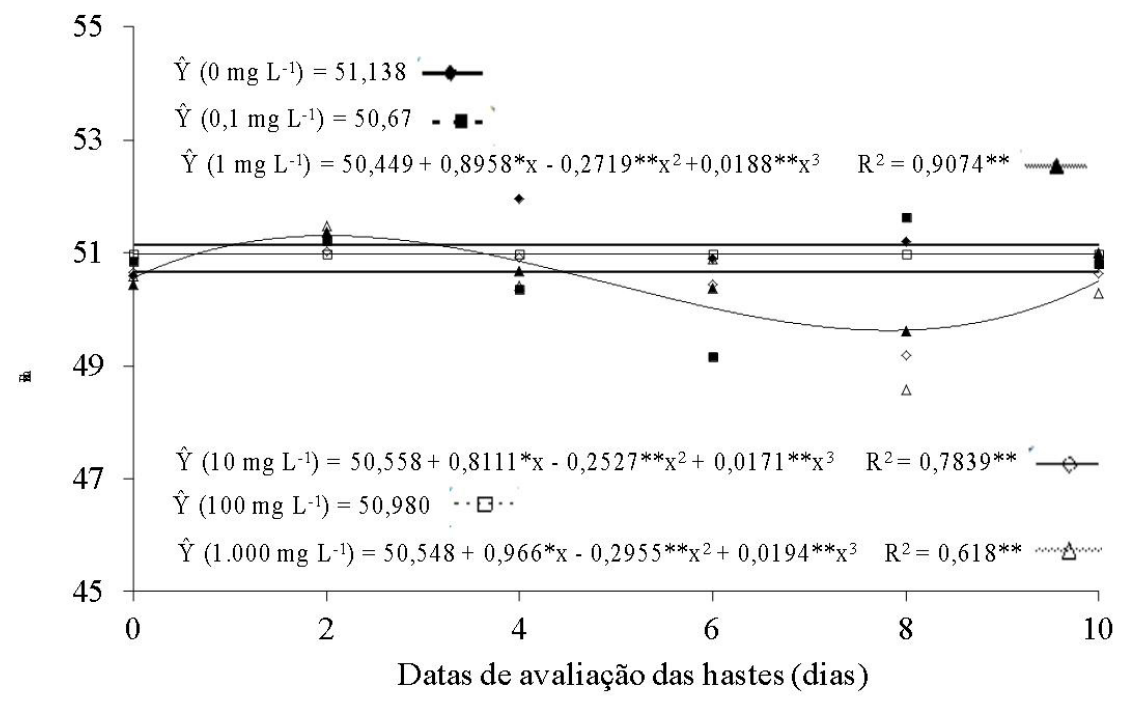

(A)

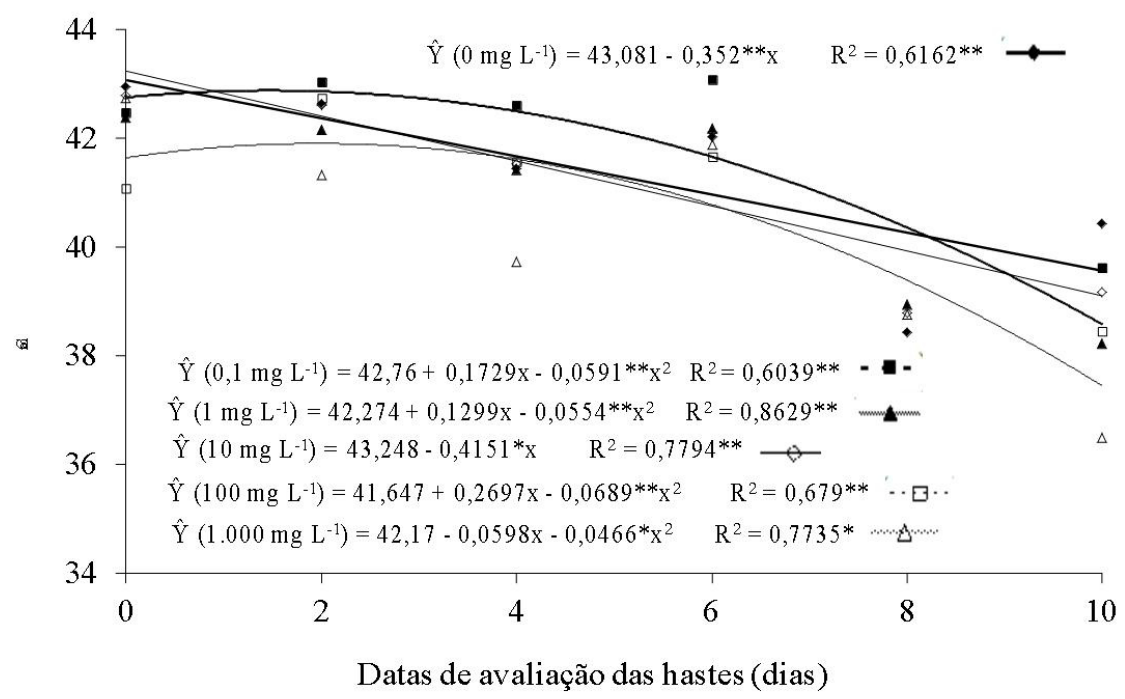

Figura 4. Luminosidade (A) e croma (B) das brácteas de helicônias 'Golden Torch' tratadas com $0 ; 0,1 ; 1 ; 10 ; 100$ e $1.000 \mathrm{mg} \mathrm{L}^{-1}$ de ethephon durante dez dias de armazenamento $\left(20,4 \pm 3,7^{\circ} \mathrm{C}\right.$ e $49 \pm 11 \%$ UR). Petrolina, PE, 2007.

$(*)$ e $(* *)$, significativos a $5 \%$ e a $1 \%$ de probabilidade, pelo teste " $\mathrm{t}$ ", respectivamente.

Figure 4. Lightness (A) and chroma (B) of the bracts of heliconias 'Golden Torch' treated with 0, 0.1, 1, 10, 100 and $1,000 \mathrm{mg} \mathrm{L}^{-1}$ of ethephon, for 10 days of storage $\left(20.4 \pm 3.7^{\circ} \mathrm{C}\right.$ and $\left.49 \pm 11 \% \mathrm{RH}\right)$. Petrolina,

Pernambuco State, Brazil, 2007.

(*) and (**), significant at 5\% and 1\% probability by " $t$ " test, respectively. 
A L das brácteas de inflorescências tratadas com $0 ; 0,1$ e $100 \mathrm{mg} \mathrm{L}^{-1}$ de ethephon se manteve estável até o final do armazenamento (Figura 4A). Por sua vez, nas inflorescências tratadas com 1, 10 e $1.000 \mathrm{mg} \mathrm{L}^{-1}$, os maiores valores de $\mathrm{L}$ foram observados até o terceiro e ao décimo dia de avaliação. As variações e a diminuição da $\mathrm{L}$ das brácteas em relação aos valores iniciais foram mais distintas naquelas tratadas com $1.000 \mathrm{mg} \mathrm{L}^{-1}$ de ethephon, que por sua vez, podem estar associadas às modificações nos teores de água e/ ou no perfil dos pigmentos carotenóides durante o armazenamento das inflorescências. No entanto, esclarece-se que a faixa de variação dos valores foi restrita, desde aproximadamente 49 até 52, no máximo. Esta variação não evidencia, na prática, diferenciações claras entre os tratamentos, apesar de se esperar que maiores perdas de massa fresca, como observado para o tratamento com 1.000 mg.L - $^{-1}$, repercutam em perda de brilho. Segundo Ayranci e Tunc (2003), a perda de brilho é o reflexo da perda de água causada pela transpiração, contribuindo para o escurecimento do produto, sendo ainda, relacionado com a perda de pigmentos devido a danos oxidativos (DE PIETRO et al., 2012).

Os valores médios de croma das brácteas diminuíram com o aumento das concentrações de ethephon e com o tempo de armazenamento (Figura 4B). As hastes florais tratadas com 100 e $1.000 \mathrm{mg} \mathrm{L}^{-1}$ de ethephon caracterizaram-se, ao final de dez dias de avaliação, pela menor intensidade ou pureza da cor laranja quando comparadas às do controle. O decréscimo no croma das brácteas representa mudança da cor laranja puro ao laranja pardo pela redução da saturação e o aumento do componente cinza (VIÑA et al., 2007). Esses dados indicam modificações no perfil dos pigmentos presentes nas brácteas de helicônias 'Golden Torch', com perda de carotenóides intensificada pelo ethephon, principalmente na dose de $1.000 \mathrm{mg} . \mathrm{L}^{-1}$. Em outros estudos com flores de abóbora de inverno (Cucurbita maxima Duch.), Seroczyńska et al. (2006) relataram correlação positiva nos valores do croma com os teores de $\beta$-caroteno e carotenóides totais, refletindo em maior intensidade da cor das flores.

Os valores do ângulo Hue das brácteas de inflorescências tratadas com 0; 0,1 e $100 \mathrm{mg} \mathrm{L}^{-1}$ de ethephon decresceram até o quinto dia de armazenamento, sendo que, a partir desse período, houve aumento. Segundo Eason e Webster (1995), para flores de Sandersonia aurantiaca (Hook.), que é uma espécie insensível ao etileno e possui coloração alaranjada, o aumento nos valores do ângulo Hue indica perda de pigmento e início de senescência.

No entanto, comportamento diferente foi observado para as hastes de helicônias 'Golden Torch' tratadas com 1,10 e $1.000 \mathrm{mg} \mathrm{L}^{-1}$ de ethephon, que apresentaram dois momentos de decréscimo nos valores de ângulo Hue, sendo um ocorrido até ao terceiro e o outro a partir do oitavo dia de avaliação, indicando alteração da cor laranja para o laranja avermelhado. Esta resposta pode estar relacionada a modificações metabólicas na síntese, expressão, degradação e concentração de pigmentos, e ainda, a mudanças nos teores de água dos tecidos durante o armazenamento. Segundo Shigeoka et al. (2002), todos os fatores envolvidos em estresses e na senescência, inclusive o etileno exógeno, levam a uma série de mudanças fisiológicas e processos de desorganização celular, danos oxidativos nos lipídios, proteínas, pigmentos, entre outros, formando produtos tóxicos e afetando as membranas celulares. Como processos de desorganização celular levam a respostas irregulares, é possível que a influência sobre os carotenoides, pigmentos que variam desde amarelo a vermelho, tenha ocorrido em graus e momentos diferenciados.

Em relação às doses de ethephon aplicadas, os menores valores de ângulo Hue foram observados nas hastes tratadas com $0 ; 0,1 ; 1$ e $10 \mathrm{mg} \mathrm{L}^{-1}$, quando comparadas às que receberam as doses de 100 e $1.000 \mathrm{mg} \mathrm{L}^{-1}$ (Figura 5A). Nas hastes tratadas com as duas maiores doses de ethephon, os maiores valores de ângulo Hue representaram a coloração laranja pálido, indicativa da degradação dos pigmentos presentes nas brácteas.

As respostas da cor das brácteas foram comparáveis às de outros autores. Em espécies sensíveis ao etileno exógeno, como por exemplo, flores de Epidendrum ibaguense Kunth., há mudança de coloração do laranja para o vermelho nas pétalas e no labelo com a aplicação de ethephon nas concentrações de 10, 100 e $1.000 \mathrm{mg} \mathrm{L}^{-1}$ (MORAES et al., 2007). No caso de $S$. aurantiaca, Eason et al. (1997) encontraram resultados semelhantes para o ângulo Hue das tépalas de flores mantidas em água de vaso, desde a maturação até a senescência. Segundo esses autores, a mudança na coloração de amarelo para o laranja claro aconteceu quando as flores alcançaram a maturação completa, sendo a senescência caracterizada pela descoloração (reversão do laranja para o amarelo pálido) e pela murcha, que ocorreram inicialmente nas extremidades das tépalas e progrediram para as partes superiores das flores.

A aparência e a qualidade pós-colheita das hastes florais de helicônia 'Golden Torch' foram limitadas com a aplicação de doses crescentes de ethephon (Figuras 5B e 6). As flores tratadas com 0,$1 ; 1 ; 10 ; 100$ e $1.000 \mathrm{mg} \mathrm{L}^{-1}$ de ethephon apresentaram, ao décimo dia de avaliação, em média, notas de aparência e qualidade inferiores às do tratamento controle em aproximadamente $2 \%, 6 \%, 1 \%, 12 \%$ e $39 \%$, respectivamente. A perda de qualidade ocorreu mais precocemente nas inflorescências tratadas com 100 e $1.000 \mathrm{mg}$ $\mathrm{L}^{-1}$ de ethephon, que exibiram precocemente sinais de murcha e escurecimento das brácteas, desidratação das extremidades, curvatura das hastes e abscisão das flores. Segundo Woltering e Van Doorn (1988), muitas flores, nas quais a murcha é a causa primária dos sintomas de senescência, não são sensíveis ao etileno exógeno, enquanto aquelas flores que têm a abscisão como sintoma inicial de senescência geralmente são sensíveis ao etileno exógeno.

A longevidade das inflorescências foi influenciada pelas doses de ethephon. As inflorescências tratadas com 100 e $1.000 \mathrm{mg} \mathrm{L}^{-1}$ de ethephon tiveram sua longevidade reduzida drasticamente em dois e quatro dias, respectivamente. No quarto e sexto dia de armazenamento, as inflorescências tratadas com $1.000 \mathrm{mg} \mathrm{L}^{-1}$ de ethephon possuíam $31 \%$ e $100 \%$, respectivamente, notas de aparência inferior a 2 pela escala subjetiva de notas. Para as inflorescências tratadas com $100 \mathrm{mg} \mathrm{L}^{-1}$ do produto, a redução foi em torno de $56 \%$, que ocorreu a partir do oitavo dia de armazenamento, enquanto que as tratadas com $0 ; 0,1 ; 1$ e $10 \mathrm{mg} \mathrm{L}^{-1}$ de ethephon apresentavam, neste dia, uma redução na longevidade em cerca de 38\%, 44\%, 31\% e 6\%. Essa resposta corro- 

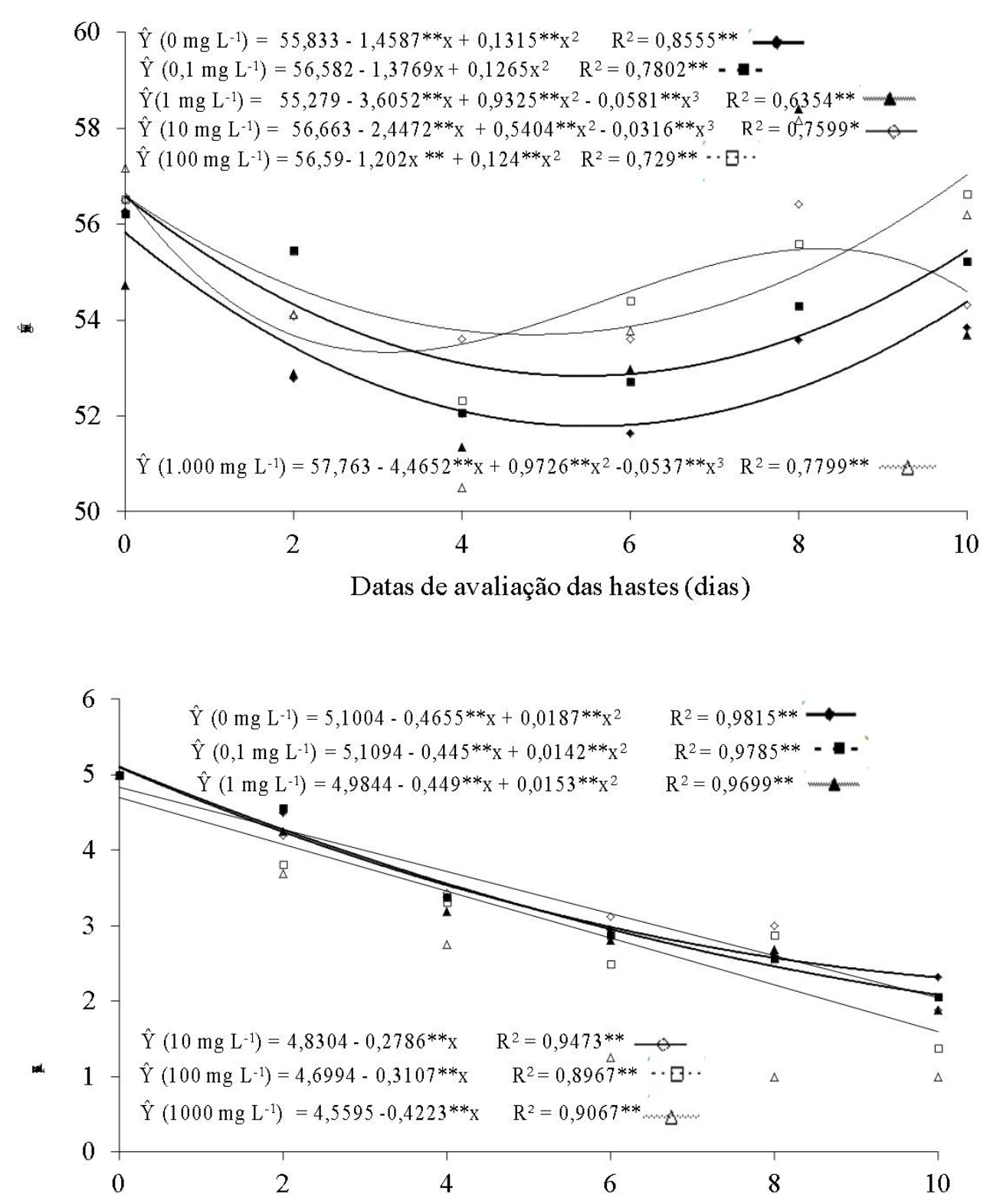

Datas de avaliação das hastes (dias)

Figura 5. Ângulo Hue (A) e aparência (B) das brácteas de helicônias 'Golden Torch' tratadas com 0; 0,1;1;10;100 e $1.000 \mathrm{mg} \mathrm{L}^{-1}$ de ethephon durante dez dias de armazenamento $\left(20,4 \pm 3,7^{\circ} \mathrm{C}\right.$ e $49 \pm 11 \%$ UR). Petrolina, PE, 2007.

$(*)$ e $(* *)$, significativos a $5 \%$ e a $1 \%$ de probabilidade, pelo teste "t", respectivamente.

Figure 5. Hue angle (A) and appearance (B) of the bracts of heliconias 'Golden Torch' treated with 0, 0.1, 1, 10, 100 and 1,000 $\mathrm{mg} \mathrm{L}^{-1}$ of ethephon, for 10 days of storage $\left(20.4 \pm 3.7{ }^{\circ} \mathrm{C}\right.$ and $\left.49 \pm 11 \% \mathrm{RH}\right)$. Petrolina, Pernambuco State, Brazil, 2007.

$(*)$ and $(* *)$, significant at $5 \%$ and $1 \%$ probability by " $t$ " test, respectively.

bora a proposição de que as inflorescências de helicônias 'Golden Torch' possuem pouca sensibilidade ao etileno exógeno, respondendo apenas a altas concentrações. Ao décimo dia de avaliação, $94 \%, 82 \%, 100 \%, 94 \%$ e $100 \%$ das inflorescências tratadas, respectivamente, com 0,$1 ; 1$; $10 ; 100$ e $1.000 \mathrm{mg} \mathrm{L}^{-1}$ de ethephon apresentavam sintomas de senescência, enquanto no controle essa percentagem foi de $69 \%$.

Com base no que foi observado, pode-se afirmar que a senescência somente foi antecipada quando as inflorescências foram expostas a altas concentrações de ethephon (100 e $1.000 \mathrm{mg} \mathrm{L}^{-1}$ ). Os sintomas de senescência intensificados pelo uso do ethephon, com restrição na aparência das inflorescências, incluíram murcha, necrose e escurecimento das brácteas; amarelecimento e curvatura da haste; e abscisão de flores, que podem ter sua causa primária no desequilíbrio entre as taxas de absorção e perda de água, gerando déficit hídrico e redução da longevidade. 

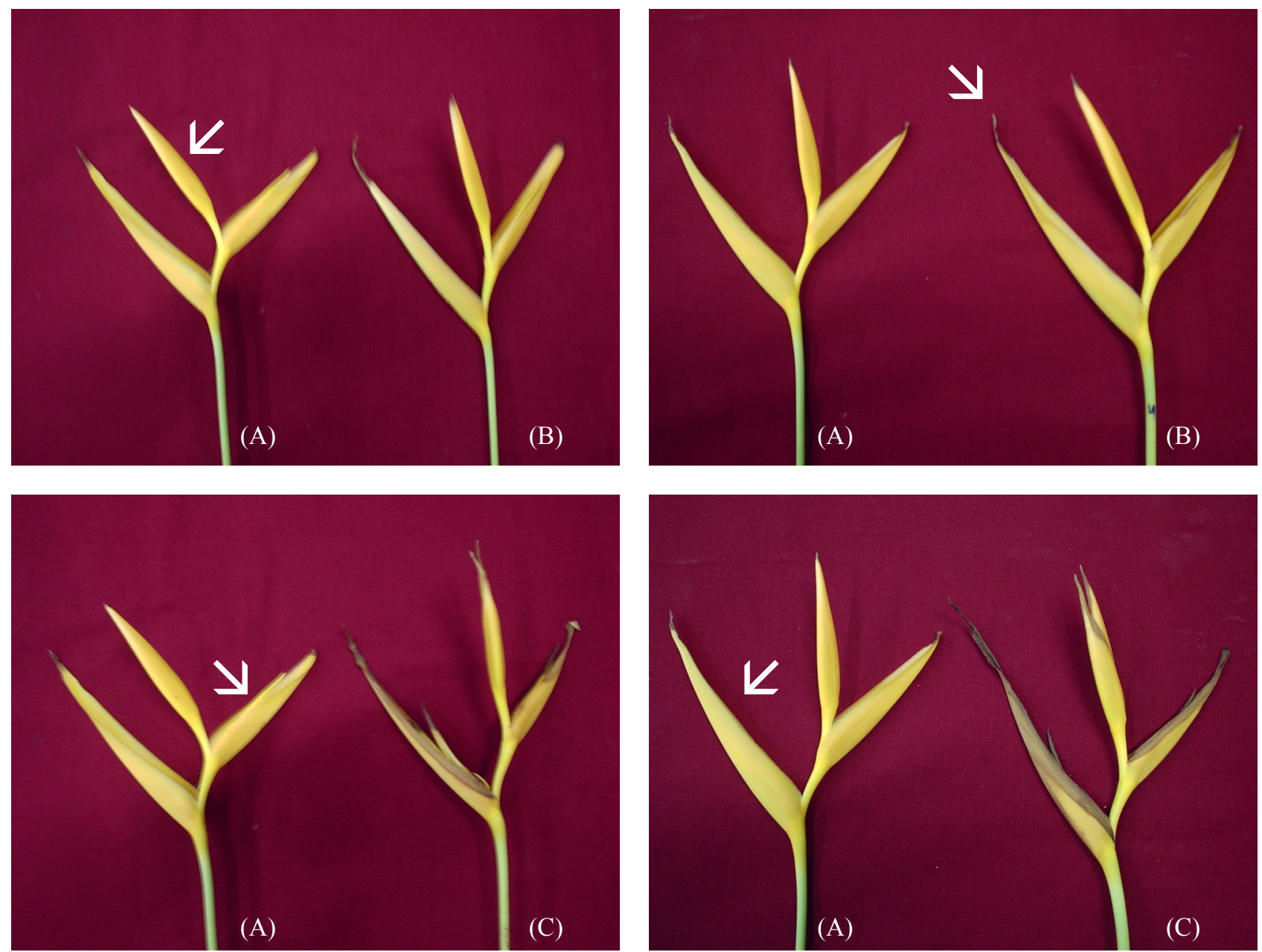

Figura 6. Aparência visual de inflorescências de helicônias 'Golden Torch' tratadas com 0, 100 e $1.000 \mathrm{mg} \mathrm{L}^{-1} \mathrm{de}$ ethephon (A, B e C, respectivamente) e avaliadas aos oito e dez dias de armazenamento $\left(20,4 \pm 3,7^{\circ} \mathrm{C}\right.$ e $\left.49 \pm 11 \% \mathrm{UR}\right)$. As setas indicam os sintomas de senescência associados com escurecimento, necrose e perda de turgidez das brácteas.

Petrolina, PE, 2007.

Figure 6. Appearance of heliconias 'Golden Torch' inflorescences treated with 0, 0.1, 1, 10, 100 e 1,000 $\mathrm{mg} \mathrm{L}^{-1} \mathrm{of}$ ethephon ( $A, B$ and $C$, respectively) and evaluated after eight and ten days of storage $\left(20.4 \pm 3.7^{\circ} \mathrm{C}\right.$ and $\left.49 \pm 11 \% \mathrm{RH}\right)$. The arrows indicate the symptoms of senescence associated with browning, necrosis and turgidity loss of the bracts. Petrolina, Pernambuco State, Brazil, 2007.

\section{CONCLUSÕES}

As inflorescências de helicônia 'Golden Torch' são pouco sensíveis ao etileno exógeno.

A antecipação da senescência somente ocorre quando são aplicadas doses de ethephon de 100 e $1.000 \mathrm{mg} \mathrm{L}^{-1}$.

Apesar da necessidade de técnicas de conservação para helicônia 'Golden Torch', não se justifica a aplicação de inibidores de etileno na pós-colheita.

\section{AGRADECIMENTOS}

Ao Conselho Nacional de Desenvolvimento Científico e Tecnológico (CNPq), pela concessão de bolsa; e às instituições Embrapa Semiárido e Universidade Federal de Viçosa, pelo apoio financeiro na condução e no desenvolvimento deste trabalho.

\section{REFERÊNCIAS}

AYRANCI, E.; TUNC, S. A method for the measurement of the oxygen permeability and the development of edible films to reduce the rate of oxidative reactions in fresh foods. Food Chemistry, Washington, v. 80, p. 423-431, 2003.

BUNYA-ATICHART, K.; KETSA, S.; VAN DOORN, W. G. Postharvest physiology of Curcuma alismatifolia flowers. Postharvest Biology and Technology, Amsterdam, v. 34, n. 2, p. 219-226, 2004.

CAStro, A. C. R. de; LOGES, V.; COSTA, A. S. da; CASTRO, M. A. F. de; ARAGÃO, F. A. S. de; WILLADINO, L. G. Hastes florais de helicônia sob deficiência de macronutrientes. Pesquisa Agropecuária Brasileira, Brasilia, v. 42, n. 9, p. 1299-1306, 2007. 
CHAMANI, E.; KHALIGHI, A.; JOYCE, D. C.; IRVING, D. E.; ZAMANI, Z.A.; MOSTOFI, Y.; KAFI, M. Ethylene and anti-ethylene treatment effects on cut 'First Red' rose. Journal of Applied Horticulture, Lucknow, v. 7, n. 1, p. 3-7, 2005.

DE PIETRO, J.; MATTIUZ, B; MATTIUZ, C. F. M.; RODRIGUES, T. J. D. Qualidade de rosas de corte tratadas com produtos naturais. Ciência Rural, Santa Maria, v. 42, n. 10, p. 1781-1788, 2012.

DIAS-TAGLIACOZZO, G. M.; FINGER, F. L; BARBOSA, J. G. Fisiologia pós-colheita de flores de corte. Revista Brasileira de Horticultura Ornamental, Campinas, v. 11, n. 2, p. 89-99, 2005.

EASON, J. R.; DE VRÉ, L.; SOMERFIELD, S. D.; HEYES, J. A. Physiological changes associated with Sandersonia aurantiaca flower senescence in response to sugar. Postharvest Biology and Technology, Amsterdam, v. 12, n. 1, p. 43-50, 1997.

EASON, J. R.; WEBSTER. D. Development and senescence of Sandersonia aurantiaca (Hook.) flowers. Scientia horticulturae, Amsterdam, v. 63, p. 113-121, 1995.

ELGAR, H. J.; WOOLF, A. B.; BIELESKI, R. L. Ethylene production by three lily species and their response to ethylene exposure. Postharvest Biology and Technology, Amsterdam, v. 16, n. 3, p. 257-267, 1999.

FINGER, F. L.; BARBOSA, J. G. Fisiologia e manejo pós-colheita de flores tropicais. In: NOGUEIRA, R. J. M. C.; ARAÚJO, E. de L.; WILLADINO, L. G.; CAVALCANTE, U. M. T. (Org.). Estresses ambientais: danos e benefícios em plantas. 1 ed. Recife: MXM Gráfica e Editora, v. 1, p. 287-295, 2005.

FINGER, F. L.; BARBOSA, J. G. Postharvest physiology of cut flowers. In: NOUREDDINE, B.; NORIO, S. Advances in postharvest technologies for horticultural crops. 1 ed. Kerala: Research Signpost, v. 2, n. 37/ 661, p. 373-393, 2006.

GAGO, C. M. L.; MONTEIRO, J. A. NAA and STS effects on bract survival time, carbohydrate content, respiration rate and carbohydrate balance of potted Bougainvillea spectabilis Willd. Postharvest Biology and Technology, Amsterdam, v. 60, n. 2, p. 235-243, 2011.

IMSABAI, W.; KETSAB, S.; VAN DOORN, W. G. Role of ethylene in the lack of floral opening and in petal blackening of cut lotus (Nelumbo nucifera) flowers. Postharvest Biology and Technology, Amsterdam, v. 58, n. 1, p. 57-64, 2011.

JUNQUEIRA, A. H.; PEETZ, M. S. Os pólos de produção de flores e plantas ornamentais do Brasil: uma análise do potencial exportador. Revista Brasileira de Horticultura Ornamental, Campinas, v. 8, n. 1/2, p. 25-47, 2002.

LANDGRAF, P. R. C.; PAIVA, P. D. O. Produção de flores cortadas no estado de Minas Gerais. Ciência e Agrotecnologia, Lavras, v. 33, n. 1, p. 120-126, 2009.
MA, N.; TAN, H.; LIU, X.; XUE, J.; LI, Y.; GAO, J. Transcriptional regulation of ethylene receptor and CTR genes involved in ethylene-induced flower opening in cut rose (Rosa hybrida) cv. Samantha. Journal of Experimental Botany. London, v. 57, p. 2763-2773, 2006.

MORAES, P. J.; FINGER, F. L; BARBOSA, J. G; CECON, P. R. Longevidade pós-colheita de orquídea Epidendrum ibaguense. Revista Brasileira de Horticultura Ornamental, Campinas, v. 13, n. 1, p. 31-37, 2007.

NOWAK, J.; RUDNICKI, R. M. Postharvest handling and storage of cut flowers greens, and potted plants. Timber Press: Portland, p. 45-46, 1990.

SEBRAE, Pernambuco se destaca na produção de flores tropicais e tradicionais. Recife: SEBRAE/PE, 2008. Disponível em: http://www.portaldoagronegocio.com.br/ conteudo.php?id=24838. Acesso em 09 set., 2010.

SEREK, M.; WOLTERING, E. J.; SISLER, E. C.; FRELLO, S.; SRISKANDARAJAH, S. Controlling ethylene responses in flowers at the receptor level. Biotechnology Advances, Atlanta, v. 24, p. 368-381, 2006.

SEROCZYŃSKA, A.; KORZENIEWSKA, A.; SZTANGRET-WIŚNIEWSKA， J.; NIEMIROWICZSZCZYTT, K.; GAJEWSKI, M. Relationship between carotenoids content and flower or fruit flesh colour of winter squash (Cucurbita maxima Duch.). Folia Horticulturae, Krakow, v. 18, n. 1, p. 51-61, 2006.

SHIGEOKA, S.; ISHIKAWA, T.; TAMOI, M.; MIYAGAWA, Y.; TAKEDA, T.; YABUTA, Y.; YOSHIMURA, $\mathrm{K}$. Regulation and function of ascorbate peroxidase isoenzymes. Journal of Experimental Botany, Oxford, v. 53, n. 371, p. 1305-1319, 2002.

SOUZA, S. O. de. Longevidade de Heliconia psittacorum x H. spathocircinata 'Golden Torch' e H. bihai em resposta ao uso de reguladores de crescimento. 2008. 158 f. Tese (Doutorado em Fitotecnia) - Universidade Federal de Viçosa, Viçosa, MG.

TAN, H.; LIU, X.; MA, N., XUE, J.; LU, W.; BAI, J.; GAO, J. Ethylene-influenced flower opening and expression of genes encoding Etrs, Ctrs, and Ein $3 s$ in two cut rose cultivars. Postharvest Biology and Technology, Amsterdam, v. 40, n. 2, p. 97-105, 2006.

TANASE, K; ONOZAKI, T.; SATOH, S.; SHIBATA, M.; ICHIMURA, K. Differential expression levels of ethylene biosynthetic pathway genes during senescence of long-lived carnation cultivars. Postharvest Biology and Technology, Amsterdam, v. 47, n. 2, p. 210-217, 2008.

VAN DOORN, W. G.; CRUZ, P. Evidence for a wounding-induced xylem occlusion in stems of cut chrysanthemum flowers. Postharvest Biology and Technology, Amsterdam, v. 19, n.1, p. 73-83, 2000. 
VAN DOORN, W. G.; PERIK, R. R. J.; ABADIE, P.; HARKEMA, H. A treatment to improve the vase life of cut tulips: effects on tepal senescence, tepal abscission, leaf yellowing and stem elongation. Postharvest Biology and Technology, Amsterdam, v. 61, n.1, p. 56-63, 2011.

VIÑA, S. Z.; MUGRIDGE, A.; GARCÍA, M. A.; FERREYRA, R. M.; MARTINO, M. N.; CHAVES, A. R.; ZARITZKY, N. E. Effects of polyvinylchloride films and edible starch coatings on quality aspects of refrigerated Brussels sprouts. Food Chemistry, Washington, v. 103, p. 701-709, 2007.
WOLTERING, E. J.; VAN DOORN, W. G. Role of ethylene in senescence of petals: Morphological and taxonomical relationship. Journal of Experimental Botany, London, v. 208, p. 1605-1616, 1988.

YAMAMOTO, K.; KOMATSU, Y.; YOKOO, Y.; FURUKAWA, T. Delaying flower opening of cut roses by cis-propenylphosphonic acid, Journal of the Japanese Society for Horticultural Science, Kyoto, v. 63, n. 159166, 1994. 